\title{
The Role of Universities' Electronic Management in Achieving Organizational Excellence: Example of Al Hussein Bin Talal University
}

\author{
Dima Waswas ${ }^{1} \&$ Mustafa Jwaifell ${ }^{1, *}$ \\ ${ }^{1}$ Department of Curriculum and Instruction, Faculty of Educational Sciences, Al-Hussein Bin Talal University, Jordan \\ *Correspondence: Department of Curriculum and Instruction, Faculty of Educational Sciences, Al-Hussein Bin Talal \\ University, Jordan. E-mail: jwaifell@hotmail.com, jwaifell@ahu.edu.jo. https://orcid.org/0000-0002-7279-7253
}

Received: May 6, 2019

Accepted: June 8, 2019 Online Published: June 24, 2019

doi:10.5430/wje.v9n3p53

URL: https://doi.org/10.5430/wje.v9n3p53

\begin{abstract}
The study aimed at identifying the level of applying electronic management and the organizational excellence at Al-Hussein Bin Talal University (AHU). It also attempted to predict the organizational excellence level through the degree of applying electronic management. The study sample consisted of (249) administration members (academic managers, managers) at AHU. The study tool considered two sections: the first concerned measuring the level of applying electronic management with regard to three dimensions (administrative, materialistic, and technical); the second concerned identifying the organizational excellence level with regard to three dimensions (leadership excellence of university management, human staff excellence, and services excellence). A descriptive methodology was used to accomplish the study objectives.

The study results showed that the level of applying electronic management at AHU is average with regard to administrative and technical dimensions, while it is poor regarding the materialistic dimension. It also revealed that the level of organizational excellence is average on the leadership excellence dimension but poor on human staff excellence and services excellence dimensions. The study includes detailed analysis of the classified variables (work position, experience years, work place). Linear regression analysis also showed that the level of organizational excellence achievement's degree can be predicted through identifying the degree level of applying electronic management at AHU.
\end{abstract}

Keywords: electronic management, organizational excellence, Al Hussein Bin Talal University

\section{Introduction}

The rapid development of information and communication technology has led to the emergence of a new paradigm and style of management in the face of competition and the increasing challenge under bureaucratic administrations to improve their business and quality of services. Such an aspect has been called as electronic management or e-government management. E-management is the lifeblood of contemporary life and a modern alternative to the development of human life, which meets his administrative demands, and satisfies his ambition to obtain higher capabilities that are easier in managing his life affairs and details. Therefore, the application of electronic management in institutions is an urgent need and a motivation to overcome administrations problems, and achieve organizational excellence at a rapid pace.

\section{Electronic Management}

The intervention of information and communication technologies is a considerable revolution regarding management because of the great change it brings to management style and effectiveness. In fact, electronic management means moving from traditional work to information applications, including computer networks, to connect organizational units with each other, which facilitates access to data and information to make appropriate decisions, accomplish work, and satisfy customers' needs in an efficient, cost-effective and fast manner. More precisely, electronic management is a complete digital system designed to transform the traditional administrative work from manual to electronic depending on strong information systems that helps make management decisions faster and cost less. Thus, it provides a number of benefits, such as speed of work, decision-making, reducing administration costs, overcoming 
the problem of geographical and temporal dimensions, and addressing bureaucracy (Kubaisi, 2008).

Al-Salami, Al-Kilani, Al-Bayani, and Dergham (2006, p.235) define Electronic Management as a "process of automating all the tasks and activities of the administrative institution based on all the necessary information technologies to achieve the new objectives of management in reducing the use of paper, simplifying procedures, eliminating the routine and achieving fast and accurate completion of tasks and transactions; so that each administration is ready to connect with the e-government later." Whereas Mohammed (2009, p. 43) defines it as "the execution of procedures and transactions that take place between two or more parties, whether individuals or institutions, through the use of electronic communication networks."

Radwan (2004) pointed to the reasons why traditional institutions shift to electronic management, like: complexity of procedures and processes and their impact on increasing the cost of labor, inability to merge data all over the institution, the difficulty of increasing competition among institutions, and the need for having mechanisms of excellence within each institution that seek competition and the desire to provide new models of services such as e-learning as a flexible and almost openly available service, and expanding the use of computers and its various software on computer networks of all kinds.

The application of e-management is one of the strategies that have a number of advantages for the benefit of the institution, like: decreasing the cost of administrative procedures, reducing the time needed to complete administrative transactions, providing completed operations with accuracy and objectivity, having the ability to correct errors quickly, sharing documents with other departments as fast as possible, diminishing bureaucracy, and reducing the impact of personal relationships on accomplishing work (Seydo, 2015). Hamzawy, Al-Nimr, and Fashqji (2011) also added other benefits to the application of electronic management in institutions, such as the possibility of applying the business remotely, increasing and enhancing competitiveness, and being compatible with the developed world.

Since electronic management is important for the development of administrative work and improving the different institutions, in addition to the many advantages that institutions benefit from because of applying electronic management, universities seek to keep up on recent changes, and use electronic management in decision-making processes. In other words, managing the administrative and educational process takes place by using computers and electronic devices. Here are some examples of administrative applications of electronic management and the services it provides within universities,

1) Field of Student Affairs: Among the services provided by e-management is distributing students to the departments, following up students' attendance and absence, and extracting students' results to analyze and evaluate them. (Al-Najjar, Ghazzawi, and Najjar, 2003)

2) Personnel affairs: It helps in dealing with personnel files in terms of entering, organizing and maintaining their data and addresses, providing the different types of services needed by staff at all levels, and following up the employees' evaluation through performance monitoring programs. (Al-Lami, 2008)

3) The field of managing university affairs: The role of electronic management appears through its applications with regard to following up various university affairs, identifying its coming needs, and providing different services, like:

- Communication applications including the use of internal and external communication networks to enter data and give guidance related to work and communicating with other institutions.

- Office applications including Microsoft Word that accomplish written administrative work and contribute to preparing internal business reports in, university plans, and writing letters to the concerned party.

- Preparation of the weekly lecture schedule: Electronic management helps in preparing the weekly lecture schedule and distributing it to faculty members and students with minimal effort and time.

- The field of university supplies: It includes constructing a file for all university supplies like furniture and appliances.

- University Budget: University budget depends on university fees. And the university administration can use the computer to handle financial matters, save them and distribute them to activities according to certain percentages. It also monitors expenses to make it easy for accountants to check them with ease.

- University library: It includes computerizing libraries, providing a database to search for books and sources with reference numbers to classify them. (Al-Najjar et al., 2003) 


\section{Organizational Excellence}

Organizational excellence is an intellectual style and management philosophy that depends on a methodology related to how tangible results can be achieved in the institution to achieve some balance in satisfying the needs of all parties; whether stakeholders or society at large, within a culture of learning, creativity and continuous improvement. (Assayed, 2007)

When the institution shows distinguishable performance, it will enhance the chances of its survival, for growth and excellence are two sides of the same coin. The concept of contemporary management is not just a slogan, it is an integrated system that includes all the modern management activities and techniques to raise the level of performance and achievement to higher degrees that make the institution excel on other competitors. In other words, excellence is not a coincidental achievement, but rather it is achieved through the overall efforts of the workers in the contemporary organization at all levels. (Al-Salami, 2001)

Excellence is defined as "the skill of managing the organization and achieving objectives based on a set of core practices that include focusing on results, caring for clients, leadership, goal stability, process management, continuous improvement, creativity, mutual benefits among institutions, social responsibility and accomplishing interests for individuals and society." (Aldallal, 2005, p.27)

Excellent company is characterized by vitality, flexibility, innovation and openness. It also focuses on the vision, mission and goals. It conducts a strategic analysis of the internal and external environment in order to identify strengths, weaknesses, opportunities and challenges which pave the way for formulating appropriate strategies that ensure achieving excellence in performance and developing competitive capabilities (Al-Dori, 2010). The ultimate objective of implementing the dimensions of organizational excellence is to achieve a developmental leap in the institutional performance that helps leaders acquire ambitions for achieving efficiency and excellence in performance on a global level. This is reflected in enriching the spirit of competition in all fields and activities of the organization (Ghazi, 2014). The importance of organizational excellence stems from the institutions' ability to crystallize the forces supporting excellence by achieving rapid rates of change, accomplishing unlimited competition, maintaining organizational space and status (human resources, organizational culture, organizational structure), raising the sense of quality, and having the ability to use technology in information and creativity (Zayed, 2003). In this way, institutions in the modern era adopt an administrative thought in order to achieve excellence in response to a set of motives that supports excellence and aims to achieve it. Some of the motives are:

1) The rapid change in the environmental conditions surrounding the institution that affect its activity and decisions (Belhawi, 2007).

2) Unlimited competition since economic globalization has changed the limits of competition through the emergence of new competitors (Yassin, 2008).

3) Growing of Quality Concept: The increase in demanding quality has made many organizations realize that they have to provide services with high quality in order to successfully compete, so quality has become a fundamental criterion for achieving organizational excellence.

4) Information Technology revolution: it is reflected in the means used to produce, distribute and use information in all forms; written, audiovisual, and visual (Kundalji, Assamerraa'i, 2009).

Literature Review:

Studies on the application of electronic management in universities: Abu-Ashour and Al-Nimri (2013) conducted a study aimed at detecting the level of applying electronic management at Al-Yarmouk University. The study used the analytical descriptive method. Results showed that the level of applying electronic management at Al-Yarmouk University from the viewpoint of faculty members was high, while it was average from the viewpoint of managers.

Al-Hassanat (2011) study aimed at identifying the obstacles in applying electronic management in Palestinian universities. The study used a descriptive survey method. Results revealed that there are serious attempts by Palestinian universities to implement electronic management, and that there are organizational, technical, human and financial obstacles that might appear during the application of electronic management in Palestinian universities.

The study of Mraish (2011) aimed to identify the contribution of electronic management in developing administrative work in the institutions of higher education. The study used the descriptive approach to achieve the study objectives. Results showed that there is a statistically significant relationship between the use of hardware and software, communication networks and knowledge makers and the development of administrative work.

The study of Felck (2010) aimed at revealing the extent of using electronic management in managing administrative 
departments in universities. Results showed that $67 \%$ of department heads have adequate knowledge of computers and wish to apply it in their administrative work. The results also indicated a positive relationship between computer knowledge and the level of using it in electronic management.

Studies on organizational excellence: The study of Laframboise (2002) aimed to determine the criteria for measuring the outstanding performance. It used the social survey approach. The study results showed that the main criteria for achieving outstanding performance are: financial performance, impact of product quality, quality processes, role of customers, role of employees, and the behavior of stakeholders.

Al-Nsour (2010) study aimed to reveal the impact of the educated organization characteristics in achieving organizational excellence in the Jordanian Ministry of Higher Education and Scientific Research. The results showed that the level of having the characteristics of the educated organization in the Jordanian Ministry of Higher Education and Scientific Research was average, and that the level of applying the dimensions of organizational excellence (Leadership excellence, excellence of human resources, excellence in operations, excellence in knowledge, financial excellence) was also average.

Saada (2013) study aimed at identifying the extent of applying the leadership standard in institutions of higher education according to the European model of excellence. The results found that there is a relative increase in the standard of leaders' interaction with students and concerned parties, the standard of leaders' development of vision, mission, and value system comes next, then the standard of leaders' efforts in developing, applying, and improving the administrative system comes last.

Al-Bohsi (2014) study aimed to identify the role of enabling employees to achieve organizational excellence in technical colleges in the Gaza Strip. The study results indicated that the respondents agree on the availability of administrative empowerment in their faculties. They also agree on the availability of organizational excellence in its leadership, human and services dimensions to a large extent.

\section{Method}

\subsection{Statement of the Problem}

The application of electronic management is a new administrative approach that achieves a lot of advantages for the institution. It contributes to the speed of completing work, reducing the level of costs, handling bureaucracy, simplifying procedures and reducing the use of paper in the process of preservation and documentation.

AHU is one of the Jordanian government universities that seek to introduce electronic management applications into its various units. Electronic management represents a profound revolution in management and its methods and applications that lead to achieving organizational excellence in terms of service delivery, improving the quality of performance, and developing the skills of employees. Thus, the study aims to investigate the level of applying electronic management and the level of organizational excellence at AHU and to indicate whether it is possible to predict the level of achieving organizational excellence through the degree of application of electronic management at AHU.

\subsection{The Study Significance}

The importance of the current study is determined by the following aspects:

1) The study deals with an administrative issue of a great importance, characterized by modernity and the role of electronic management in achieving organizational excellence.

2) It is hoped that the results of this study and its recommendations to decision makers in the Jordanian universities will lead to the intervention of electronic management applications in all administrative and service aspects of the universities.

3) A measuring tool was developed to predict the level of achieving organizational excellence through the degree of applying electronic management at AHU. It is possible to take advantage of this tool and apply it in universities and other institutions.

\subsection{Objectives of the Study}

The study aims to investigate the role of e-management in AHU by answering the following questions:

1) What is the level of applying electronic management at AHU?

3) Are there statistically significant differences at $\alpha \leq 0.05$ between the means of applying e-management at AHU 
according to the variables: gender, job position, years of experience, workplace?

3) What is the level of achieving organizational excellence at AHU?

4) Is it possible to predict the degree of achieving organizational excellence through the degree of applying e-management at AHU?

\subsection{Limitations}

1) Geographic: AHU in Ma'an Governorate - Jordan.

3) Time: The second semester of the academic year 2017/2018.

4) Human: The staff of AHU, who hold an administrative position and academics with administrative position in addition to their duties as faculty scholars.

5) The results of the study are limited by the method of sample selection, the validity of the study instrument and its reliability, and the statistical measurements used to answer its questions.

\subsection{Definitions}

1) Electronic management: A modern system based on electronic technology and aims to transform the traditional management to electronic management that depends on the use of computer and its applications in the administrative, materialistic and technical aspects of the institution, measured by the degree of to the sections of the study tool on the axes of applying electronic management.

2) Organizational excellence: that the university achieves a high level of performance regarding leadership and human staff and provides services to beneficiaries, measured by the degree of response of the study members' response to the sections of the study tool on the axes of the level of organizational excellence.

\subsection{The Study Population and Sample}

The study population consists of all members of the administrative board who hold only administrative status, and faculty academics who have administrative positions in addition to their duties as instructors (administrative academic) at Al Hussein Bin Talal University. The number of managers is (225) and the number of academic managers is (61) members.

The study sample was consisted of all members of the study population. However, the questionnaires that were approved for the study were (49) questionnaires by academic managers $(80 \%)$ and (200) questionnaires by managers $(89 \%)$; the reason for this is the absence of some people and the elimination of some questionnaires unacceptable for analytical purposes. Therefore, (249) individuals with $87 \%$ of the total study population (286) were included in the study. The demographic description of the study sample is as follows:

Table 1. The Study Population and Its Sample

\begin{tabular}{|c|c|c|c|c|}
\hline \multirow[t]{2}{*}{ Variables } & & \multicolumn{2}{|c|}{ Gender } & \multirow{2}{*}{ Total } \\
\hline & & Male & Female & \\
\hline \multirow[t]{2}{*}{ Job Position } & Manager & 118 & 82 & 200 \\
\hline & Academic Manager & 33 & 16 & 49 \\
\hline Total & & 151 & 98 & 249 \\
\hline \multirow[t]{3}{*}{ Years of Experience } & $1-5$ & 41 & 23 & 64 \\
\hline & $6-10$ & 32 & 19 & 51 \\
\hline & More than 10 & 78 & 56 & 134 \\
\hline Total & & 151 & 98 & 249 \\
\hline \multirow{3}{*}{ Workplace } & Humanitarian & 32 & 12 & 44 \\
\hline & Scientific & 36 & 23 & 59 \\
\hline & Unit & 83 & 63 & 146 \\
\hline Total & & 151 & 98 & 249 \\
\hline
\end{tabular}

\subsection{Measurement Tools}

To achieve the study objectives, two tools were used: the first is to measure the level of applying electronic management, and the second is to measure the level of achieving organizational excellence. The following steps have been taken to develop them: 
1) The previous studies were analyzed. Thus, the following studies were used to develop the electronic management tool (Abu-Ashour and Al-Nimri, 2013; Al-Hassanat, 2011; Mraish, 2011), also Al-Nsour (2010) and Al-Bahaisi (2014) to develop the Organizational excellence tool.

2) The validity of the measurement tools: The items of the tools were developed and presented to a group of referees of university professors for validity, and to ensure the correct wording of the linguistic items, how related it is to the domain it reflects, and its suitability to achieve the study objectives. The necessary amendments have been made in the light of the referees' observations. The indicators of the validity of the study tools structure were calculated by calculating the coefficient correlation of each paragraph to its dimension and the total tool under which it was found. Then it was concluded that all the tools items are statistically significant.

3) The reliability of the measurement tools: The reliability of the tools during the application was calculated by the coefficient of internal consistency (Cronbach's Alpha) between the items of each dimension and the total items of each instrument as shown in the following table:

Table 2. The Validity and Reliability of the Measurement Tool ( $\mathrm{N}=249)$

\begin{tabular}{lllll}
\hline Tools & Domains excellence & $\begin{array}{l}\text { Items } \\
\text { Number }\end{array}$ & $\begin{array}{l}\text { Cronbach's } \\
\text { Alpha }\end{array}$ & $\begin{array}{l}\text { Pearson } \\
\text { coefficient }\end{array}$ \\
\hline e-management & Administrative & 19 & 0.916 & $0.942^{* *}$ \\
& Materialistic & 7 & 0.905 & $0.850^{* *}$ \\
& Technical & 8 & 0.914 & $0.858^{* *}$ \\
\hline Total & & 34 & 0.954 & \\
\hline Organizational excellence & Leadership & 13 & 0.932 & $0.909^{* *}$ \\
& Human resources & 13 & 0.941 & $0.942^{* *}$ \\
& Services & 13 & 0.945 & $0.931^{* *}$ \\
\hline
\end{tabular}

Table (2) shows that the reliability coefficients of the study instruments are high; their internal consistency is high and can be considered very suitable for the study purposes.

4) The study tools scale: The answers for the tools items were measured to reflect the degree of applying e-management and the degree of achieving organizational excellence to a five-point scale of (1-5) degree of application and degree of achievement and the scores of the study tools were divided into five categories, for the purpose of judging the level of applying electronic management, and the degree of achieving organizational excellence as: very poor $=1-1.80$, poor $=1.81-2.60$, average $=2.61-3.40$, good $=3.41-4.20$, very good $=4.21-5$, respectively.

\subsection{The Study Methodology}

The analytical methodology was used to develop the study tools, and the descriptive methodology to determine the level of applying electronic management and the degree of achieving educational excellence according to the variables: Gender, Job position: managers, academic managers, Years of Experience: 1-5 years, 6-10 years, more than 10 years, and Workplace: a humanitarian college, a scientific college, university units, centers and deanships that are not within the faculties (Units). While the measured variables: applying electronic management, organizational excellence.

The predictor variables are: Applying Electronic Management: It has three levels: administrative application, materialistic application, technical application. The predated variable is Organizational Excellence.

\section{Results and Discussion}

The Analyses of the resulting ratio data were performed using descriptive statistics. Descriptive measures including means and standard deviations for applying e-management and organizational excellence were calculated to answer the questions of the study. Results according to the questions of the study were as follow:

\subsection{Question1: What is the Level of Applying Electronic Management AHU?}

To answer the study first question, means and standard deviations of the first study instrument Items were calculated, the level of applying e-management and the rank of each item as shown in Appendix (A): 


\subsubsection{The Level of Applying Electronic Management Regarding Administrative Domain}

- Item (2) reflecting the availability of an electronic personnel management system in the university, and paragraph (10) reflecting the university's electronic systems for recording employees' attendance and absence, ranked a high degree of application.

- Items $(1,3,4,5,6,8,9,11,12,13,15,16,17$, and 19) ranked average degree.

- Item (7) reflecting the university's giving incentives for employees who excel in the use of electronic management, item (14) reflecting the university's application of electronic means in assessing employees' performance, and item (18) reflecting the university's having of an electronic database to help it graduated students, ranked a low degree of application.

- Item (10) ranked the highest degree, and paragraph (14) ranked the lowest degree.

\subsubsection{The Level of Applying Electronic Management Regarding Materialistic Domain}

- Items $(20,21$, and 24) have an average degree of application.

- Items $(22,23,25$, and 26) have a low degree of application.

- Item (24) reflecting how the university connects all its facilities with an intranet ranked the highest degree, while item (26) reflecting the availability of a telefax machine to facilitate doing electronic work ranked the lowest degree.

\subsubsection{The Level of Applying Electronic Management Technical Domain}

- All the items related to the domain of technical application ranked an average degree of application.

- Item (33) reflecting the availability of various electronic communication tools such as e-mail in the university's website ranked the highest degree with a mean (3.10) and a standard deviation (1.13), while item (34) reflecting the availability of electronic models of academic work such as course syllabus preparation ranked the lowest degree with a mean (2.71) and a standard deviation (1.14).

Means and standard deviations were calculated according to applying e-management and its domains. Thus, it was observed that there were differences among means to the level of applying electronic management and the crucial score corresponding to the minimum of the previous level category (2.60) in each of the total of applying e-management and its domains. To determine the significance of the differences, T-test was used for each sample as shown in Table (3):

Table 3. Results of One Sample T-Test for Applying E-Management ( $\mathrm{N}=249)$

\begin{tabular}{lclllcl}
\hline Domains & Mean & SD & Rank & Crucial Score & T value & Sig \\
\hline Administrative & 3.01 & 0.73 & Average & 2.60 & 8.837 & $.000(\mathrm{a})$ \\
Materialistic & 2.65 & 0.94 & & & 0.813 & .417 \\
Technical & 2.90 & 0.87 & & & 5.46 & $.000(\mathrm{a})$ \\
Applying e-management & 2.91 & 0.72 & Average & 2.60 & 6.73 & $.000(\mathrm{a})$ \\
\hline
\end{tabular}

T-test results of t-test showed that the level of applying e-management at AHU is at the average level regarding the administrative application, the technical application, and the total level of applying e-management with a statistical significance at $(\alpha \leq 0.05)$. However, the mean difference of the materialistic domain from the crucial score (2.60); which represents the highest level of the low-level application category, was not statistically significant at $(\alpha \leq 0.05)$. Thus, the degree of the materialistic domain application falls into the category of low application.

The result of this study agreed with the study of Abu-Ashour and Al-Nimri (2013) in that the level of applying electronic management was average from the viewpoint of managers.

This result can be explained by the fact that the level of applying electronic management at AHU has reached an average level for both the administrative and materialistic dimensions and the low level of the technical dimension, because AHU is working hard to introduce electronic management in its administrative, technical and materialistic applications to facilitate and improve the quality of performance. However, it is quite clear that there are obstacles regarding the materialistic aspect that the university faces, and this is evidenced by the university's inability to provide the necessary financial resources to equip the infrastructure of electronic management, and the inability to provide a sufficient number of scanners and telefaxes due to the financial distress experienced by the university. 
5.2 Question 2: Are there statistically significant differences at $\alpha \leq 0.05$ between the means of applying e-management at AHU according to the variables: gender, job position, years of experience, workplace?

In order to answer the second question, means and standard deviations were calculated according to gender, work position, years of experience, and place of work:

5.2.1 Gender: There were observed differences between the statistical means of the gender variable on the degree of applying electronic management and its domains. To determine the significance of the differences, two sample t-test was used for to determine Gender significance differences, as shown in Table (4):

Table 4. Means and Standard Deviations According to Gender and Two Sample T-Test Results ( $\mathrm{df}=247)$

\begin{tabular}{llccccc}
\hline Domains & Gender & $\mathrm{N}$ & Mean & SD & $\mathrm{t}$ & Sig \\
\hline Administrative & Male & 151 & 3.07 & 0.70 & \multirow{2}{*}{1.737} & \multirow{2}{*}{0.084} \\
& Female & 98 & 2.91 & 0.75 & & \\
Materialistic & Male & 151 & 2.75 & 0.88 & \multirow{2}{*}{2.205} & \multirow{2}{*}{0.036} \\
& Female & 98 & 2.49 & 1.00 & & \\
Technical & Male & 151 & 2.94 & 0.84 & \multirow{2}{*}{0.897} & \multirow{2}{*}{0.371} \\
\multirow{4}{*}{ Applying e-management } & Female & 98 & 2.84 & 0.93 & & \\
& Male & 151 & 2.97 & 0.69 & \multirow{2}{*}{1.793} & \multirow{2}{*}{0.074} \\
& Female & 98 & 2.81 & 0.76 & & \\
\hline
\end{tabular}

The results of independent samples t-test showed no statistically significant differences at $(\alpha \leq 0.05)$ between the means in applying e-management at AHU according to gender for applying e-management, administrative, and technical except for applying materialistic domain in favor of males. The results partly agreed with the results of Abu Abu-Ashour and Al-Nimri study (2013) that there are no gender differences in the two domains.

Those findings can be explained by the fact that the employees of AHU, both male and female managers and academic mangers, are all subject to a single administrative system and a similar materialistic environment, but it is clear that there are differences regarding the materialistic dimension and in favor of males because the percentage of male respondents was higher than that of females. Moreover, most respondents are managers who are more sensitive to the materialistic deficiencies in applying electronic management in their administrative work due to the continuity in administrative work.

5.2.2 Work Position: There were observed differences between the statistical means of the gender variable on the degree of applying electronic management and its domains. To determine the significance of the differences, two sample t-test was used for to determine Gender significance differences, as shown in Table 5:

Table 5. Means and Standard Deviations According to Work Position and Two Sample T-Test Results $(\mathrm{df}=247)$

\begin{tabular}{llccccc}
\hline Domains & Work Position & $\mathrm{N}$ & Mean & SD & $\mathrm{t}$ & Sig \\
\hline Administrative & Manager & 200 & 3.00 & 0.70 & \multirow{2}{*}{0.105} & \multirow{2}{*}{0.916} \\
Materialistic & Academic Manager & 49 & 3.02 & 0.82 & & \\
\multirow{3}{*}{ Technical } & Manager & 200 & 2.69 & 0.92 & \multirow{2}{*}{1.421} & 0.157 \\
& Academic Manager & 49 & 2.48 & 1.02 & & \\
Applying e-management & Manager & 200 & 2.97 & 0.85 & \multirow{2}{*}{2.647} & 0.009 \\
& Academic Manager & 49 & 2.61 & 0.89 & & \\
& Manager & 200 & 2.93 & 0.70 & \multirow{2}{*}{1.061} & 0.290 \\
\hline
\end{tabular}

The results of the T-test showed no statistically significant differences at $(\alpha \leq 0.05)$ between the means of applying e-management at AHU based on work position for applying e-management and on the administrative and materialistic domains; except for technical domain in favor of the administrative work position.

This result can be explained by the fact that many of the technical administrative tasks are assigned to the university managers, so the manager is more familiar with the technical matters in the university than the faculty academics.

5.2.3 Years of Experience and Work Place: The means and standard deviations were calculated, as shown in Table (6): 
Table 6. Means and Standard Deviations According to Years of Experience and Work Place

\begin{tabular}{llcll}
\hline Classified Variables & & $\mathrm{N}$ & Mean & SD \\
\hline Years of Experience & $1-5$ & 64 & 2.89 & 0.76 \\
& $6-10$ & 51 & 2.98 & 0.72 \\
Work Place & More than 10 & 134 & 2.91 & 0.72 \\
& Humanitarian & 44 & 3.01 & 0.72 \\
& Scientific & 59 & 3.01 & 0.66 \\
& Unit & 146 & 2.84 & 0.74 \\
\hline
\end{tabular}

There were observed differences between the means of years of experience and the means workplace on the level of applying electronic management. To determine the significance of the differences, One way ANOVAtest was used, as shown in Table 7:

Table 7. ANCOVA Summery According to Years of Experience and Work Place

\begin{tabular}{lllllll}
\hline Source of Variance & & Sum of Squares & df & Mean Square & F & Sig. \\
\hline Years of experience & Between groups & 0.339 & 2 & 0.17 & 0.324 & 0.724 \\
& Within groups & 128.785 & 246 & 0.524 & & \\
\hline Workplace & Between groups & 1.806 & 2 & 0.903 & 1.745 & 0.177 \\
& Within groups & 127.318 & 246 & 0.518 & & \\
\hline
\end{tabular}

The results of ANOVA analysis showed no statistically significant differences at $(\alpha \leq 0.05)$ between the means of applying e-management at $\mathrm{AHU}$, according to years of experience and work place.

The results of this study were consistent with the study of Abu-Ashour and Al-Nimri (2013) that there are no statistically significant differences related to workplace. This result can be explained by the fact that all levels of years of experience are familiar with the applying electronic management at the university, and they use of its applications in their work. The university also deals equally with all faculties and units and seeks to distribute electronic administrative services according to needs.

\subsection{Question 3: What is the level of achieving organizational excellence in AHU?}

To answer the third question, means and standard deviations of the second instrument items were calculated, the level of achieving excellence and the rank of each, one sample t-test was used on the crucial score representing the upper limit of the level of achieving excellence that precedes the observed category to determine achieving excellence level. The following is a summary of one sample t-test results:

Table 8. Results of One Sample T-Test for Achieving Organizational Excellence ( $\mathrm{N}=249)$

\begin{tabular}{lllllll}
\hline Domains & Mean & SD & Rank & Crucial Score & T value & Sig \\
\hline Leadership & 2.87 & 0.78 & Average & 2.60 & 5.504 & $.000(\mathrm{a})$ \\
Human resources & 2.54 & 0.84 & Poor & 1.80 & 13.933 & $.000(\mathrm{a})$ \\
Services & 2.69 & 0.86 & Average & 2.60 & 1.578 & .116 \\
Organizational Excellence & 2.70 & 0.77 & Average & 2.60 & 2.076 & $.000(\mathrm{a})$ \\
\hline
\end{tabular}

Table 9 shows that there are statistically significant differences at $(\alpha \leq 0.05)$ at the level of achieving organizational excellence at AHU on leadership excellence domain, total organizational excellence at the average level, and human resources excellence at the poor level, while there is no statistically significant difference on service excellence dimension, where the difference between the average (2.7) and the marginal mark (2.6) is not statistically significant, and therefore the level of service excellence is poor.

This result partly agreed with the results of Al-Nsour study (2010), that the level of applying leadership excellence was average. And it differed with regard to the domain of human staff which in the study of Al-Nsour was average while in this study it is with a poor degree of application.

The result can be explained by the fact AHU has achieved an average level of excellence for the leadership domain in managing the university; that there are efforts and development plans at the administrative level that seek to 
develop and improve administrative processes constantly, improve the requirements of the university environment and adopt an open door policy to identify the needs of students and employees. But these efforts need more planning and development and adopting innovative strategies for implementation so that the level of achievement increases more.

As for why the domain of the human staff had a low level of excellence, it is may be due to the weakness in the development system of university staff, having limited training courses for new faculty members which do not satisfy the changing academic needs, the weak system of motivating employees, not involving employees in the preparation of development plans, and the lack of innovative tools that contribute to the completion of work with high quality.

The reason why services excellence domain occupied a low level of application is probably due to the fact that provided services are not constantly developed by the university, in addition to not receiving the proper feedback by employees for the sake of improving the level of services.

5.4 Question 4: Is it possible to predict the degree of achieving organizational excellence through the degree of applying e- management at AHU?

In order to answer the fourth question by measuring the relationship between the domain of the level of applying electronic management and its relation to the level of achieving organizational excellence, the multiple linear regression analysis was used by the 'Enter' method through entering all the independent variables in the linear regression equation. Table 9 summarizes the results of the regression analysis:

Table 9. Summary of Multi Regression Results

\begin{tabular}{llllllllll}
\hline Dependent Variable & $\mathrm{R}$ & \multirow{2}{*}{$\mathrm{R}^{2}$} & $\mathrm{~F}$ & $\mathrm{df}$ & $\mathrm{Sig}$ & $\begin{array}{l}\text { Independent } \\
\text { Variables }\end{array}$ & $\beta$ & $\mathrm{T}$ & $\mathrm{Sig}$ \\
\hline Organizational Excellence & 0.838 & 0.702 & \multirow{2}{*}{192.037} & 3 & $.000(\mathrm{a})$ & Administrative & 0.374 & 6.695 & $.000(\mathrm{a})$ \\
& & & & 245 & & Materialistic & 0.325 & 7.511 & $.000(\mathrm{a})$ \\
& & & & & & Technical & 0.164 & 3.481 & 0.001 \\
\hline
\end{tabular}

It was noted from the table that the values of the triple correlation coefficient were $(R=0.838)$, while $\left(R^{2}=0.702\right)$ and the Adjusted $\mathrm{R}^{2}$ was (0.698), meaning that the independent explanatory variables (applying of administrative, materialistic, and technical) of the electronic management could explain almost $(0.70)$ of the variables in (the level of organizational excellence) and the rest $(0.30)$ was attributed to other factors.

As observed from the analysis of ANOVA, the value $(\mathrm{F}=194.037)$ calculated from the sample is statistically significant at the significance level $(\alpha \leq 0.05)$, which confirms the high explanatory power of the multiple linear regression model. It is also concluded from Table (9) that the independent variables (administrative, materialistic, and technical) were statistically significant according to t-test at the significance level $(\alpha \leq 0.05)$.

Based on the results of the regression analysis, the degree of achieving organizational excellence can be predicted through the degree of applying e-management at AHU. Linear regression equations were concluded using the Unstandardized Coefficient Beta of the organizational excellence equation at AHU:

\section{Organizational excellence in $\mathrm{AHU}=$}

\section{$0.244+(0.374 *$ Management $)+(0.225 *$ Materialistic $+(0.374 *$ Technical $)$}

It can be noted from this result that it is possible to predict the level of achieving organizational excellence through the degree of applying electronic management at AHU. The e-management has a clear and effective role in achieving organizational excellence by improving the quality of work performance at the university through the use of efficient, affective and fast electronic ways, improving the administrative work, updating its electronic tools, increasing the level of services provided to students and staff at the university, and enhancing communication among employees through various electronic communication channels, which contributes to reducing expenses and time for the completion of work. This leads to a direct impact in raising the level of organizational excellence both at the level of leadership, human staff, or services provided.

\section{Conclusion}

This study revealed the importance of e-management, its role in achieving organizational excellence and its 
efficiency, and how organizational excellence can be predictable by e-management through its domains of administrative, materialistic, and technical applications. These findings have implications for efforts to give more attention to the role of e-management, therefore including e-management in strategically planning as an important goal that should be achieved. Beside of that there have to be more workshops to overcome the lack of skills in some e-management competencies and reconsider the budget of the university to assure the use of e-management. Furthermore researches can be expanded at AHU University by using system analyses in a comparison with other university to have benefits of external experience.

\section{Recommendations}

In light of the previous study results, it is recommended that:

1) Universities should seek to expand the introduction of electronic management applications to all their work and facilities because of their clear role in achieving organizational excellence.

2) Universities should establish a system of incentives for employees who use of electronic management applications.

3) Universities should seek to provide materialistic supplies that contribute to activating the use of electronic management applications such as scanners, digital cameras and Telefax.

4) To prepare training programs for employees in universities based on modern training needs that contribute to the development of new and old employees skills in using electronic management applications and computer in all fields.

5) The selection of staff at the university should happen according to a set of standards to achieve efficiency and excellence.

\section{References}

Abu-Ashour, Khalifeh \& Al-Nemri, Deana. (2013). The The Level of Applying Electronic Administration at Yarmouk University as Percived by Administrators and Faculty Members. Jordan Journal of Educational Sciences, 9(2), 199-220.

Al-Ataiwi, Saleh. (2005). Information technology Leader of the Waves of Change in Business Organizations. The Third Administrative Forum, Development Management and Development Requirements in Administrative Work, Towards a New Active Changed Management. Jeddah, Saudi Arabia.

Al-Bohsi, abd Al-Muti. (2014). The Role of empowering employees in achieving organizational excellence "A field study in Technical Colleges in Gaza strip". Unpublished thesis, Al-Azhar University-Gaza.

Aldallal, Mohamed. (2005). "Performance Evaluation using self Assessment Approach and EFQM Excellence Model" the case of Abu. Dhaab. police College, for Master Degree, University of Bradford.

Al-Douri, Zakaria. (2010). Strategic Management: Concepts, Processes and Study skills. Dar Al Yazuri, Amman, Jordan.

Al-Hassanat, Sari. (2011). Favors Obstacles of Applying Electronic Management in the Palestinian Universities. Unpublished thesis, University of Ain Shams University.

Al-Lami, Awad. (2008). The Reality of Using Computer Applications in the Field of School Management. Unpublished Theses, College of Education, Gulf University, Bahrain.

ALmansour, Y. (2012). The impact of total quality management components on small and medium enterprises, financial performance in Jordan. Journal of Arts, Sciences \& Commence, 3(1), 87-91.

Al-Najjar, Iyad, Harsh, Ayed., Ghazzawi, Muhammad \& Najjar, Mosleh. (2003). Computer and its Educational Applications. Alam Elkutob Elhadeeth, Amman.

AL-Nosour. (2010). The Impact of Learning Organization Characteristics in Achieveing Organizational Excellence, Applied Study on the Ministry of Higher Education in Jordan. Unpublished Theses, Middle East University.

Al-Salami, Alaa, Al-Kilani, Osman \& Derghram, Hilal. (2006). Fundamentals of Management Information System. Dar Al-Maagheh, Amman, Jordan.

Al-Salmi, Ali. (2001). Human Resources Management. Dar Ggharib, Cairo, Egypt. 
Assayed, Reza. (2007). Habits of Excellence in lndividuals with Senior Management Skills. Arab Company, Cairo, Egypt.

Ayadat, Yousef. (2004). Computer in Education and its Educational Applications. Dar Al-Maseerah, Amman.

Belhawi, Saida. (2007). Development of Administration Innovation to Strategic in the Management Performances between Leader and Employees. Unpublished thesis, University of Algiers.

Felck, G. (2010). Using Computers in Cnoatia National University Divisions. Journal of Research in Higher Education, 2(1), 111-169.

Ghazi, Ali. (2014). Applied Approaches to Enhance Leadership as Enablers to Excellence. Journal of Successful Director, Excellence Series, 3, 8-12.

Hamzawy, Mohammed., Al-Nimr, Saud \& Fashqji, Hani. (2011). General Administration: Foundations and Functions. Al-Shukairy library, Riyadh.

Kubaisi, Kaltham. (2008). Requirements for the Application of Electronic Management in the Center of Information Systems of the e-government in the State of Qatar. Unpublished Theses, International Virtual University (Qatar).

Kundalji, Amer \& Assamerraa'i, Ibrahim. (2009). Information technology and Applications. Al-Warraq foundation, Amman, Jordan.

Laframboise, Kevin. (2002). AN Empinincal Study of the relationship between Quality practices and business performance excellence in central Canada. Doctoral Dissentation. Canada, Concordia University School of Graduate studies.

Mohammed, Ahmmed. (2009). Electronic Management. Dar Al-Maseerah, Amman, Jordan.

Mraish, Abdelnasser. (2011). Contribution of Electronic Administration in the Development of Administrative Work in Institutions of Higher Education. Researcher Journal Warghla University, 9, 87-100.

Radwan, raafat. (2004). Electronic Management, Second Administrative Forum of the Saudi Society of Management. Cairo, Information Center.

Saada, I. (2013). Using Applying Leadership Griterion of EFQM Excellence Model in Higher Education Institution" paper. Unpublished thesis, Business Administration Islamic University, Gaza.

Seydou, Yahya. (2015). The requirements of the application of electronic management and its obstacles in the Sudanese universities: case study at the University of Gedaref. Journal of the University of Buthana for Humanities and Social Sciences, 2(3).

Yasin, Syed. (2008). Startegic Management. Dar Elyazoory: Alryad.

Zayed, Adel. (2003). Distinguished Organizational Performance the Road to Future Organization. Arab Organization for Administrative Development, Cairo, Egypt. 


\section{Appendix A}

\section{Applying e-management: In short statements (items)}

\begin{tabular}{|c|c|c|c|c|c|}
\hline \multicolumn{2}{|c|}{ Administration } & \multirow{2}{*}{$\begin{array}{l}\text { Mean } \\
3.20\end{array}$} & \multirow{2}{*}{\begin{tabular}{|l|} 
SD \\
1.01
\end{tabular}} & \multirow{2}{*}{$\begin{array}{l}\text { Rank } \\
7\end{array}$} & \multirow{2}{*}{$\begin{array}{l}\text { Level } \\
\text { Average }\end{array}$} \\
\hline 1 & Setting regulation to for e-management & & & & \\
\hline 2 & availability of an electronic personnel management system & 3.47 & 1.01 & 2 & High \\
\hline 3 & Electronic security and archiving & 3.07 & 1.04 & 10 & Average \\
\hline 4 & Overcoming e-management literacy & 2.91 & 1.16 & 13 & Average \\
\hline 5 & Activating intranet and communication & 3.04 & 1.13 & 12 & Average \\
\hline 6 & senior management supports the implementation of electronic management & 3.25 & 1.13 & 6 & Average \\
\hline 7 & giving incentives for employees who excel in the use of electronic management & 2.35 & 1.28 & 4 & Poor \\
\hline 8 & Publishing news and announcements on the website & 3.36 & 1.07 & 3 & Average \\
\hline 9 & Using online exams & 3.29 & 1.04 & 5 & Average \\
\hline 10 & Using electronic systems for recording employees' attendance and absence & 3.64 & 1.23 & 1 & High \\
\hline 11 & Using portal for electronic services & 3.14 & 1.14 & 9 & Average \\
\hline 12 & Availability of data base for books, periodicals ...etc & 3.16 & 1.06 & 8 & Average \\
\hline 13 & Training staff on using electronic tools & 2.78 & 1.23 & 16 & Average \\
\hline 14 & evaluating staff performance electronically & 2.52 & 1.11 & 19 & Poor \\
\hline 15 & Transformation from paper work to electronic work & 2.81 & 1.08 & 15 & Average \\
\hline 16 & Encouraging using AHA e-mail & 3.06 & 1.22 & 11 & Average \\
\hline 17 & Linking SNS with AHU website & 2.82 & 1.27 & 14 & Average \\
\hline 18 & electronic database to help graduated students & 2.48 & 1.34 & 18 & Poor \\
\hline 19 & Availability of staff records database at the website & 2.78 & 1.26 & 16 & Average \\
\hline \multicolumn{2}{|c|}{ Materials } & Mean & $\mathrm{SD}$ & Rank & Level \\
\hline 20 & Availability of updated computers & 2.75 & 1.27 & 2 & Average \\
\hline 21 & Availability of printers & 2.70 & 1.21 & 3 & Average \\
\hline 22 & Availability of Scanners & 2.50 & 1.13 & 5 & Poor \\
\hline 23 & Availability of Digital Cameras & 2.55 & 1.09 & 4 & Poor \\
\hline 24 & connects all facilities with an intranet & 3.08 & 1.15 & 1 & Average \\
\hline 25 & Availability of infrastructure & 2.48 & 1.20 & 6 & Poor \\
\hline 26 & availability of a telefax & 2.47 & 1.14 & 7 & Poor \\
\hline \multicolumn{2}{|c|}{ Technical } & Mean & $\mathrm{SD}$ & Rank & Level \\
\hline 27 & Updated software & 3.00 & 1.07 & 3 & Average \\
\hline 28 & Availability of antivirus software & 2.87 & 1.13 & 5 & Average \\
\hline 29 & Availability of communication programs & 2.73 & 1.03 & 7 & Average \\
\hline 30 & LMS & 2.79 & 1.07 & 6 & Average \\
\hline 31 & Technical support staff & 3.00 & 1.16 & 3 & Average \\
\hline 32 & Programmers staff & 3.01 & 1.11 & 2 & Average \\
\hline 33 & availability of various electronic communication tools at AHU website & 3.10 & 1.13 & 1 & Average \\
\hline 34 & availability of electronic models of academic work & 2.71 & 1.12 & 8 & Average \\
\hline
\end{tabular}


Organizational Excellence: In short statements (items)

\begin{tabular}{|c|c|c|c|c|c|}
\hline \multicolumn{2}{|c|}{ Leadership } & \multirow{2}{*}{$\begin{array}{l}\text { Mean } \\
3.03\end{array}$} & \multirow{2}{*}{$\begin{array}{l}\text { SD } \\
1.04\end{array}$} & \multirow{2}{*}{$\begin{array}{l}\text { Rank } \\
2\end{array}$} & \multirow{2}{*}{$\begin{array}{l}\text { Level } \\
\text { Average }\end{array}$} \\
\hline 1 & Partnership between administrations & & & & \\
\hline 2 & Carrying out students' needs & 2.86 & 1.01 & 7 & Average \\
\hline 3 & Participation in activities, inside and outside the university & 3.08 & 0.94 & 1 & Average \\
\hline 4 & Motivating distinguish staff's performance & 2.63 & 1.12 & 13 & Average \\
\hline 5 & Improving work environment & 2.91 & 1.02 & 6 & Average \\
\hline 6 & Understanding changes that push toward excellence & 2.82 & 1.05 & 9 & Average \\
\hline 7 & Attracting resources and investments & 2.78 & 1.00 & 11 & Average \\
\hline 8 & Cooperating with local community & 2.93 & 1.00 & 5 & Average \\
\hline 9 & Open door administration & 2.99 & 1.20 & 3 & Average \\
\hline 10 & Developing work strategies & 2.82 & 1.02 & 9 & Average \\
\hline 11 & Planning for future & 2.85 & 1.03 & 8 & Average \\
\hline 12 & Universities ranking & 2.99 & 1.07 & 3 & Average \\
\hline 13 & Encouraging staff for innovative ideas & 2.65 & 1.14 & 12 & Average \\
\hline \multicolumn{2}{|c|}{ Human Resources } & Mean & SD & Rank & Level \\
\hline 14 & Developing staff competencies & 2.80 & 1.12 & 1 & Average \\
\hline 15 & Attracting high qualified personnel & 2.71 & 1.11 & 3 & Average \\
\hline 16 & Encouraging distinguish employees & 2.55 & 1.15 & 6 & Poor \\
\hline 17 & Developing new employees competencies & 2.55 & 1.08 & 6 & Poor \\
\hline 18 & Partnership in developing HR & 2.53 & 1.11 & 9 & Poor \\
\hline 19 & supplying with tools & 2.60 & 1.14 & 5 & Poor \\
\hline 20 & Scholarships for students & 2.80 & 1.04 & 1 & Average \\
\hline 21 & Measuring staff satisfy & 2.31 & 1.06 & 12 & Poor \\
\hline 22 & Scholarships for employees & 2.27 & 1.11 & 13 & Poor \\
\hline 23 & Positions according to qualifications & 2.43 & 1.04 & 10 & Poor \\
\hline 24 & Assessing staff by a clear standards & 2.55 & 1.12 & 6 & Poor \\
\hline 25 & Clear standards for recruiting & 2.61 & 1.15 & 4 & Average \\
\hline 26 & Privileges for distinguish employees & 2.39 & 1.12 & 11 & Poor \\
\hline \multicolumn{2}{|c|}{ Services } & Mean & SD & Rank & Level \\
\hline 27 & Surveying staff satisfy & 2.51 & 1.19 & 12 & Poor \\
\hline 28 & Quality assurance & 2.56 & 1.04 & 11 & Poor \\
\hline 29 & Using new means & 2.61 & 1.03 & 10 & Average \\
\hline 30 & Easiness of services & 2.64 & 1.02 & 7 & Average \\
\hline 31 & Monitoring facilities & 2.62 & 1.15 & 8 & Average \\
\hline 32 & Receiving feedback & 2.51 & 1.05 & 12 & Poor \\
\hline 33 & Formative evaluation & 2.69 & 1.04 & 6 & Average \\
\hline 34 & Respecting students & 2.84 & 1.09 & 2 & Average \\
\hline 35 & Benefits from others' experiences & 2.84 & 1.14 & 2 & Average \\
\hline 36 & Entertainments & 2.62 & 1.22 & 8 & Average \\
\hline 37 & Quality assurance of programs & 2.83 & 1.12 & 4 & Average \\
\hline 38 & Guiding students & 2.72 & 1.14 & 5 & Average \\
\hline 39 & Students' complains & 2.92 & 1.15 & 1 & Average \\
\hline
\end{tabular}

